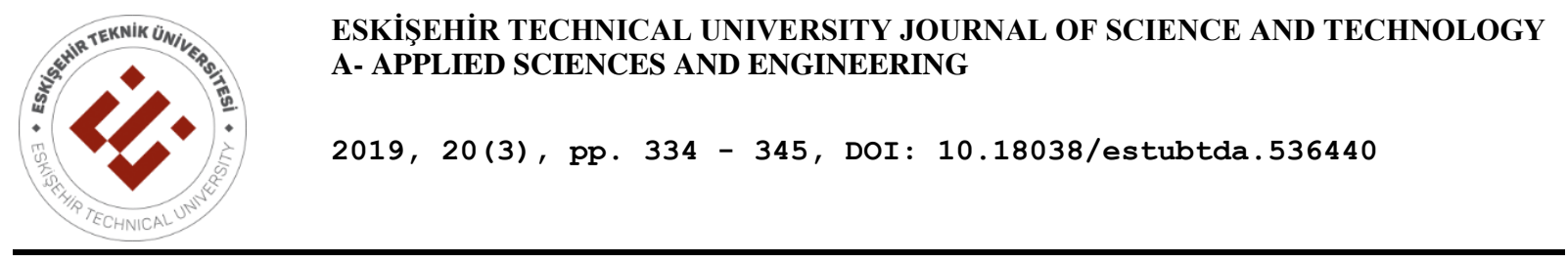

\title{
MICRO-SCALE AIR VOID STRUCTURES IN CONCRETE AND THEIR EFFECT ON FAILURE BEHAVIOR
}

\author{
Baris ARSLAN ${ }^{1, *}$, H. Selim ŞENGEL ${ }^{1}$, Mehmet CANBAZ ${ }^{1}$ \\ ${ }^{1}$ Civil Eng. Department, Faculty of Engineering and Architecture, Eskişehir Osmangazi University, Eskişehir, Turkey
}

\begin{abstract}
Tomography images and image processing methods are extensively employed by researchers to investigate the microdimensional air voids that are formed in the internal structure of concrete. Finite element method-based fracture analysis is required to investigate the effect of the mechanical behavior of concrete and micro-dimensional crack development; microdimensional voids cannot be experimentally observed because of their small scale. Although concrete that is exposed to uniaxial compression remains in the elastic region, realistic brittle failure can be achieved using the damage plasticity model, which considers the effect of tension cracks that form around micro air voids, which in turn enhance cracking development and the compressive strength of concrete. Within the scope of this study, concrete cubes with a side dimension of $15 \mathrm{~cm}$ were prepared. Three groups of these cubes are composed; each group contains three specimens. The first group contains additivefree control specimens and the remaining two groups contain specimens that are mixed with two different ratios of airentraining admixtures. After the concrete specimens were created, $1 \mathrm{~cm}^{3}$ core samples were prepared and scanned with micro computed tomography. These 2D and high-resolution images are modeled using the image processing software Simpleware and exported to the finite element method (FEM) based analysis software Abaqus. The volume, void ratio and mass properties of fresh and hardened concrete, which are experimentally obtained, are compared with the physical properties of 3D-modeled specimens. Based on the mass and volume analyses, these 3D models, which have micro-dimensional air voids that are assigned with the parametrized concrete damage plasticity (CDP) material properties were simulated, and a uniaxial compression tests and fracture analysis were performed. According to the analysis results, the relations between crack development and quantity and the distribution of entrained air were discussed.
\end{abstract}

Keywords: Concrete, Micro air voids, $\mu \mathrm{CT}$ image processing, CDP, FEM

\section{INTRODUCTION}

In global areas with air temperatures of approximately $0^{\circ} \mathrm{C}$, the durability of concrete in improperly insulated buildings, bridges, viaducts and concrete pavements subjected to poor weather conditions are at risk of the cyclic freeze-thaw effect during the winter season [1].

Water molecules that leak into the capillary voids of concrete that are continuously exposed water and moisture, freeze in cold weather. The volume of the water molecules that freeze expands $9 \%$. This volumetric expansion in concrete stabilize with the air voids in the internal structure. If an insufficient amount of air voids is available to compensate this expansion, the concrete may become damaged due to the internal stresses. Considering both cases, the amount of admixtures that are mixed with concrete to form air voids have vital control of the concrete's quality and compressive strength.

Several methods can be employed to determine the quantity of air in fresh and hardened concrete: the gravimetric method, the volumetric method and the pressure method. However, these methods do not contain any data about the distribution and qualification of voids. To determine the amount of air in hardened concrete, the microscopial determination method [2] is suggested. In this method, random cores are drilled at certain distances on cube specimens and 2D digital images, which are taken from the inner faces of this cores, are processed and examined under a stereomicroscope and the areas of the air voids and the average and standard deviations of these voids are estimated [3]. Compared with these techniques, the $\mu \mathrm{CT}$ image reconstruction techniques are preferable because they are

*Corresponding Author: barslan@live.com

Received: 06.03.2019 Published: 26.09.2019 
nondestructive methods and statistically have a high convergence ratio based on observations of air void ratios and distributions.

In this study, additive-free control groups and groups with $0.1 \%$ and $0.2 \%$ of air entraining admixtures, with a volume of $1 \mathrm{~cm}^{3}$, are produced. After scanning $\mu$-CT images, the 3D volumes of these groups are modeled and reconstructed with the image processing software Simpleware [4]. These volumes, which were meshed, were exported to the FEM-based mechanical analysis software Abaqus [5]. The quasi-static compression tests were simulated using these models, which were modeled with the concrete damage plasticity model data [6]. Fracture patterns that are dependent on the compression and tensile stresses are observed by considering the effect of micro-dimensional air voids and their distribution of the fracture behavior and the ultimate compressive strength of concrete. Image processing and the finite element method-based fracture analysis were run with an HP Z820 workstation, which has $96 \mathrm{~GB}$ of ram, dual Intel Xeon $3.10 \mathrm{GHz}$ processors and a Nvidia Quadro 6000 graphic card.

\section{MATERIALS AND MODELS}

\subsection{Properties of Specimens}

Cube specimens, which have a side length of $15 \mathrm{~cm}$, are categorized into three groups: the additivefree control group and two groups with $0.1 \%$ and $0.2 \%$ admixtures. A total of nine specimens were produced. CEM I $42.5 \mathrm{R}$ Portland cement, which achieves a 28 day ultimate compressive strength of $58 \mathrm{MPa}$, was used. The chemical, physical and mechanical properties of CEM I $42.5 \mathrm{R}$ Portland cement are listed in Table 1, the chemical properties of the air entraining admixture are listed in Table 2 and the mixing ratios for these concrete groups are listed in Table 3.

Table 1. Chemical, physical and mechanical properties of CEM I 42.5 R Portland cement

\begin{tabular}{cccccc}
\hline \multicolumn{2}{c}{ Chemical Properties (\%) } & \multicolumn{2}{c}{ Physical properties } & \multicolumn{2}{c}{ Compressive strength (MPa) } \\
\hline $\mathrm{SO} 3$ & 2.80 & Initial setting time & $150 \mathrm{~min}$ & 2 days & 28.00 \\
$\mathrm{Cl}$ & 0.02 & Volume expansion & $1 \mathrm{~mm}$ & 7 days & 47.00 \\
Loss of ignition & 3.30 & Specific surface & $3350 \mathrm{~cm}^{2} / \mathrm{g}$ & 28 days & 58.00 \\
Insoluble residue & 0.40 & & & & \\
\hline
\end{tabular}

To determine the plastic consistencies and air contents of freshly mixed concrete specimens, slump tests [7] and air content tests, respectively, were performed using the pressure method. Based on the calculation of the volume and mass properties, the unit weights of the fresh and hardened concrete specimens were determined. The physical properties of these specimens are listed in Table 4.

\subsection{Image Processing}

The SkyScan 1272 model $\mu$-CT device, which is situated in the METU-Biomaten Lab. was employed for the scanning processes of the specimens. Eight- bit grey-scale digital images with dimensions of $1000 \times 1000$ pixels, were scanned with this tomograph, which has a Hamamatsu C-9300 model $11 \mathrm{mp}$ CCD camera. The spacing of the pixels on the images is $27.45 \mu \mathrm{m}$. The specimens were scanned with the same camera under the same conditions.

After scanning the specimens, the images were imported into the Simpleware and the required adjustments were performed. The mapping of the images, which was revised to export into the finite element software Abaqus, is performed using thresholds from 0-255. The thresholds are selected for volume of interest (VOI) from 80-255. The objective of this study is to observe the effect of crack development around the micro air voids on the ultimate strength of concrete; therefore, the aggregates were ignored and modelled as concrete, as shown in Figure 2. 
Arslan et al. / Eskişehir Tech. Univ. J. of Sci. and Technology A-Appl. Sci. and Eng. 20 (3) - 2019

Table 2. Chemical properties of air entraining admixture

\begin{tabular}{lc}
\hline Chemical compound & $\begin{array}{c}\text { Fatty alcohols and } \\
\text { ammonium salts }\end{array}$ \\
Color & Light yellow \\
Density $(\mathrm{g} / \mathrm{cm} 3)$ & $0,99-1,03$ \\
$\mathrm{pH}$ & $3-7$ \\
Total chlorine (\%) & Max. 0.1, not contain \\
Water soluble chlorine $(\%)$ & Not contain \\
Amount of equivalent Alkali $(\%)$ & Max. 3 \\
\hline
\end{tabular}

Table 3. Mixing ratios in terms of units

\begin{tabular}{l|c}
\hline Mixing ratio & Unit \\
\hline Cement (CEM I 42,5 R) & 1 \\
\hline Water & 0.5 \\
\hline Sand & 2.25 \\
\hline Fine aggregate & 1.35 \\
\hline Coarse aggregate & 0.9 \\
\hline Adhesive (with \%0.1) & 0.01 \\
\hline Adhesive (with \%0.2) & 0.02 \\
\hline
\end{tabular}

Table 4. Physical properties of fresh concrete

\begin{tabular}{cccc}
\hline & Control group & $\begin{array}{c}0.1 \% \\
\text { Air Entrained }\end{array}$ & $\begin{array}{c}0.2 \% \\
\text { Air Entrained }\end{array}$ \\
\hline \multirow{2}{*}{ Unit weight } & 2.27 & 2.24 & 2.35 \\
$\left(\mathrm{~kg} / \mathrm{dm}^{3}\right)$ & 2.31 & 2.22 & 2.39 \\
& 2.33 & 2.23 & 2.33 \\
\hline$\tilde{x}_{\text {un.weight }}\left(\mathrm{kg} / \mathrm{dm}^{3}\right)$ & 2.30 & 2.23 & 2.36 \\
\hline & 20 & 23 & 16 \\
Air content $(\%)$ & 18 & 24 & 14 \\
& 17 & 24 & 16 \\
\hline$\tilde{x}_{\text {air cont. }}(\%)$ & 18 & 23.67 & 15.33 \\
\hline Slump $(\mathrm{cm})$ & 15.50 & 17.20 & 19.00 \\
\hline
\end{tabular}
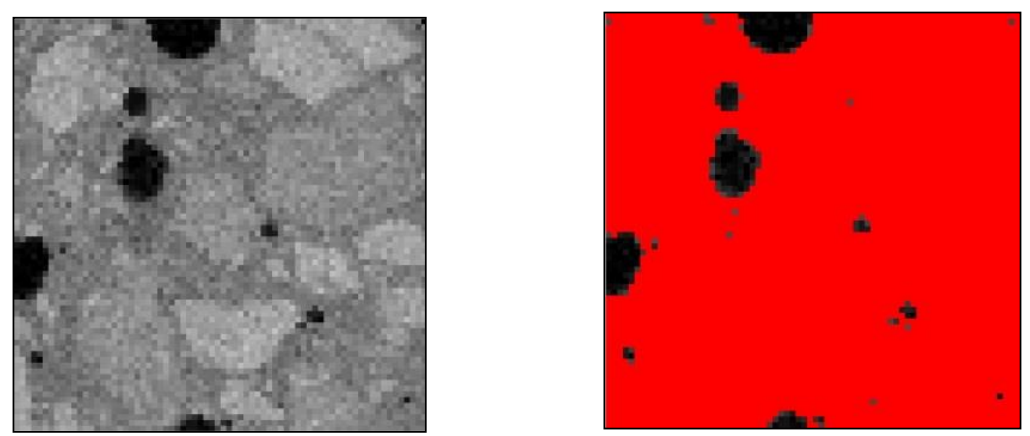

Figure 2. Eight-bit mapped image

After the implementation of the floodfill algorithm, mapped slices that were consecutively arranged were merged and models were reconstructed. Finite elements were subsequently generated on the reconstructed models using Simpleware. A smoothing algorithm and meshing were employed; a max. curvature value of 0.5 and a max iteration value of 2 selected. Both linear tetrahedral and hexahedral elements were assigned. The number of elements and the number of nodes, which were generated by the models, are listed in Table 5; 
Table 5. Number of elements and nodes generated by the models

\begin{tabular}{ccc}
\hline Model & $\begin{array}{c}\text { Number of } \\
\text { elements }\end{array}$ & $\begin{array}{c}\text { Number of } \\
\text { nodes }\end{array}$ \\
\hline Control A & 103596 & 73438 \\
Control B & 102908 & 72438 \\
Control C & 87472 & 72678 \\
\%0.1 Agency A & 161336 & 76472 \\
\%0.1 Agency B & 165950 & 77242 \\
\%0.1 Agency C & 149346 & 76450 \\
\%0.2 Agency A & 184704 & 81268 \\
\%0.2 Agency B & 226992 & 83094 \\
\%0.2 Agency C & 232598 & 83980 \\
\hline
\end{tabular}

\subsection{Concrete Damage Plasticity}

The nonlinear behavior of concrete requires the combination of two mechanical processes-plasticity and continuum damage mechanics - to examine fracture propagations. The formation of micro cracks, which are macroscopically observed produce localizations and redistributions of strain in concrete structures, which are represented as softening behaviors. This behavior can be modeled with classical plasticity [8]. The development of cracks causes micro void structures in concrete; these structural voids affect the stiffness of materials. This stiffness degradation is not easily modeled with classical plasticity. To model the fracture mechanism, continuum damage mechanics, which includes the effective stress concept [9] and can be used to characterizing post-peak softening in regard to the formation of tensile cracks, which affects the stiffness of the material, is required.

The nonlinear behavior of concrete under a periodically increasing compressive load can be explained in four stages [10]. The first stage, as shown in Figure 3, consists of 30-60\% ultimate compressive stress (45\% of U.S. in Figure 3). As shown in Figure 4.b, the maximum tensile stress in this stage is achieved on the top and bottom of the void structures and newly formed cracks appear. In this stage, the stress-strain behavior is linearly elastic and $0.3 f_{c}$ is acceptable for the elastic limit. Beyond this elastic limit, the stress-strain curve deviates from linearity and the onset of the stable fracture propagation (OSFP) region is observed. The second stage involves $60-90 \%$ ultimate compressive stress (45-85\% in Figure 3). As shown in Figure 4.c, cracks branch out due to the increasing rate of the applied force in this stage. As a result of these cracking propagations, the elastic behavior of concrete deviates from linearity, the stiffness of the material decreases and structural voids form. These structural voids result in exponentially increasing rates of strain, which causes the material to pass beyond the onset of the unstable fracture propagation (OUFP) region in the stress-strain curve. The third stage commences with the beginning of the OUFP region to the ultimate stress peak point. The main reasons for the fracture process in this stage are bonds that form between the structural voids, which produce increased dilations, as shown in Figure 4.d.

The fourth and the last stage begins beyond the ultimate stress peak point and extends to the end of the failure stress. In this stage, the main cracks are lined up in parallel directions to the applied force and form rapid separation faces in the internal structure of concrete. The energy released by the cracks exceeds the energy required for crack development. After this point, the failure mechanism achieves unstable state and crack propagations, which independently continue, and the failure mechanism ends by rupturing. 
Arslan et al. / Eskişehir Tech. Univ. J. of Sci. and Technology A-Appl. Sci. and Eng. 20 (3) - 2019
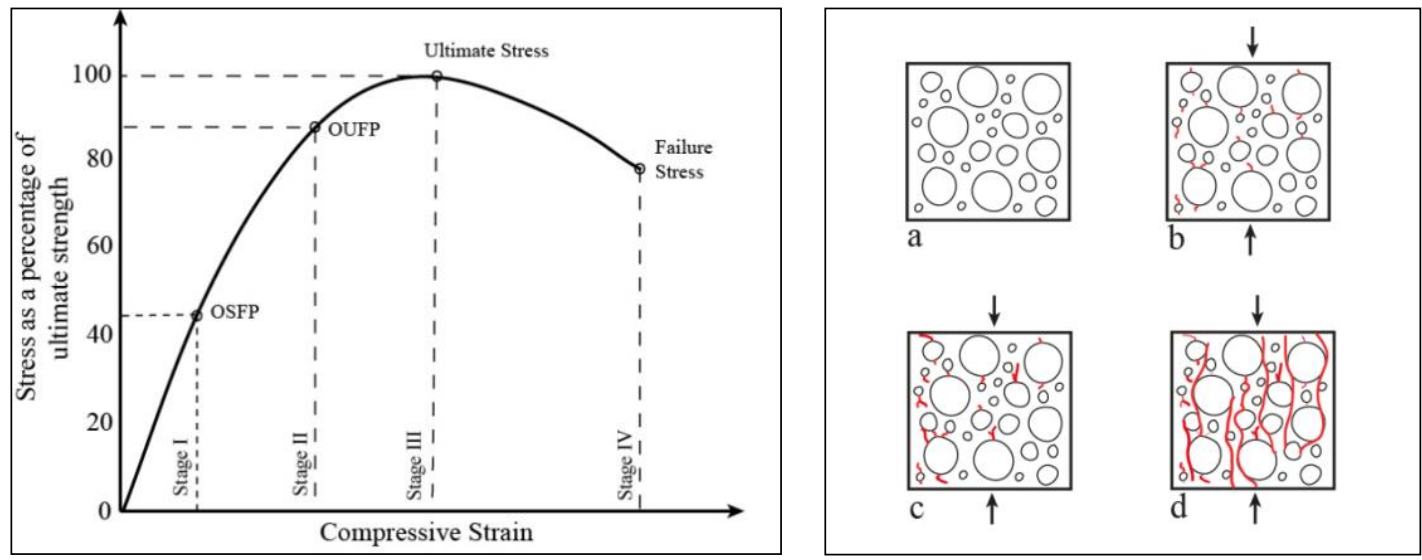

Figure 3. Stress-strain curve [10]

Figure 4. Micro crack propagation [11]

The stress-elongation curve under uniaxial tensile stress is shown in Figure 5. Elastic behavior is observed from $60-80 \%$ of the ultimate tensile stress. When the elastic limit is achieved, micro cracks begin to form around the void structures. Under uniaxial tensile stress, the formation of main cracks occur less frequently compared with the main crack propagations under uniaxial compressive stress and rapidly distribute due to unstable cracking behavior and the low tensile strength of concrete. This finding explains why concrete is a very brittle material.

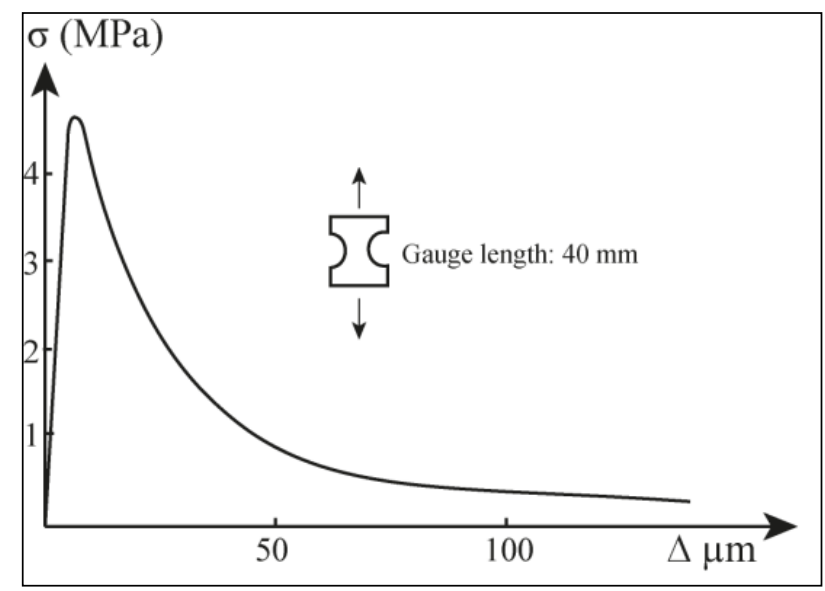

Figure 5. Uniaxial stress strain curve [12]

To determine the CDP material data, the following tests have to be performed on concrete [13]:

- Uniaxial compression;

- Uniaxial tensile;

- Biaxial failure in the plane state of stress (Kupfer's curve)

- Triaxial test of concrete

C50 concrete was subjected to these tests, and the data were parameterized for the CDP model by Jankowiak and Lodygowski [13]. The parameterized material data (listed in Table 6) are employed to model concrete in the same class. 
Table 6. Parameterized CDP material data for C50

\begin{tabular}{|c|c|c|c|}
\hline \multicolumn{4}{|c|}{ C 50 Material's parameters } \\
\hline \multicolumn{2}{|l|}{ Concrete elasticity } & \multirow{2}{*}{$\begin{array}{l}\boldsymbol{\beta} \\
\mathbf{m}\end{array}$} & \multirow{2}{*}{$\begin{array}{c}38^{\circ} \\
1\end{array}$} \\
\hline $\mathbf{E}(\mathbf{M P a})$ & 19700 & & \\
\hline \multirow[t]{2}{*}{$\mathbf{v}$} & 0.2 & $f=f_{b o} / f_{c}$ & 1.12 \\
\hline & & $\gamma$ & 0.666 \\
\hline \multicolumn{2}{|c|}{ Concrete compression hardening (MPa) } & \multicolumn{2}{|c|}{ Concrete tension stiffening (MPa) } \\
\hline Max. Comp.Stress (MPa) & $\begin{array}{l}\text { Crushing strain at max. comp. } \\
\text { stress }\end{array}$ & $\begin{array}{l}\text { Max. Ten.Stress } \\
\text { (MPa) }\end{array}$ & $\begin{array}{l}\text { Cracking strain at max. ten. } \\
\text { stress }\end{array}$ \\
\hline 50.00 & 0.000761538 & 2.842 & 0.00003333 \\
\hline \multicolumn{2}{|c|}{ Concrete compression damage (MPa) } & \multicolumn{2}{|c|}{ Concrete tension damage } \\
\hline Damage C & Crushing strain & Damage $\mathbf{T}$ & Cracking strain \\
\hline 0.195402 & 0.002557559 & 0.40611 & 0.000160427 \\
\hline 0.596382 & 0.005675431 & 0.69638 & 0.000279763 \\
\hline \multirow[t]{2}{*}{0.894865} & 0.011733119 & 0.920389 & 0.000684593 \\
\hline & & 0.980093 & 0.00108673 \\
\hline
\end{tabular}

\section{RESULTS}

\subsection{Mass Properties}

The volumes, air void ratios and average values of these data, which are obtained by analyzing the $\mu$ CT images of $1 \mathrm{~cm}^{3}$ concrete, are listed in Table 7.

Table 7. Physical properties of models

\begin{tabular}{|c|c|c|c|}
\hline & Control group & $\begin{array}{l}0.1 \% \\
\text { Admixture }\end{array}$ & $\begin{array}{l}0.2 \% \\
\text { Admixture }\end{array}$ \\
\hline \multirow{3}{*}{$\begin{array}{l}\text { Volume } \\
\left(\mathrm{mm}^{3}\right)\end{array}$} & 868.36 & 851.68 & 874.59 \\
\hline & 848.64 & 858.76 & 860.42 \\
\hline & 871.09 & 865.62 & 864.99 \\
\hline$\tilde{x}_{v o l}$ & 862.69 & 858.68 & 866.66 \\
\hline \multirow{3}{*}{ Air void ratio $(\%)$} & 13.16 & 14.83 & 12.54 \\
\hline & 15.13 & 14.12 & 13.75 \\
\hline & 12.89 & 13.43 & 13.50 \\
\hline$\tilde{x}_{\text {air void }}(\%)$ & 13.72 & 14.12 & 13.26 \\
\hline
\end{tabular}

According to the computed average air void ratios of the hardened concrete groups, which were obtained by analyzing the $\mu$-CT images, the average air void ratios of the fresh concrete groups were determined using the pressure method, as plotted in Figures 6-7. 
Arslan et al. / Eskişehir Tech. Univ. J. of Sci. and Technology A-Appl. Sci. and Eng. 20 (3) - 2019

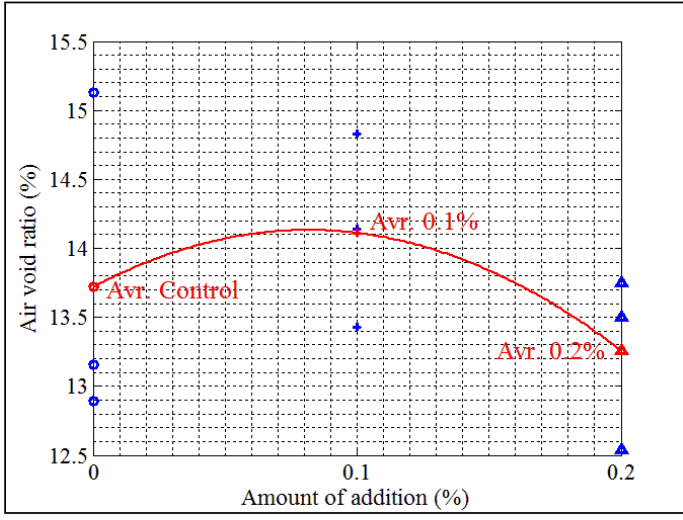

Figure 6. Computed Air void ratio

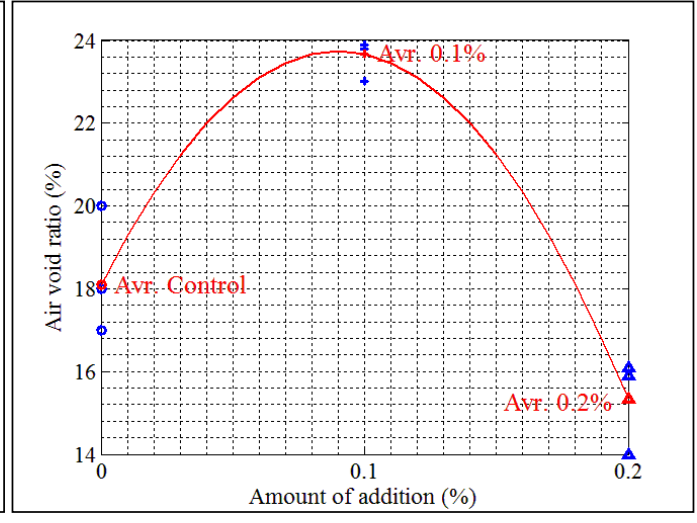

Figure 7. Experimental Air void ratio

Air entraining admixtures form air voids with a diameter that is smaller than $1 \mathrm{~mm}$ and varying diameters that range from 0.01-0.1 mm in the internal structure of concrete. As shown in Figure 8.a, entrapped air voids, which are derived from settlement problems and have diameters larger than $1 \mathrm{~mm}$, are located in the additive-free control model A. The distributions of these air voids are local and their dimensions are greater than the entrained air. In Figure 8.b, the entrapped and entrained air voids are located in model A, which is included in the group with $0.1 \%$ admixture. In Figure 8.c., only entrained air voids, which have diameters smaller than $1 \mathrm{~mm}$, are located in model A, which is included in the group with $0.2 \%$ admixture.

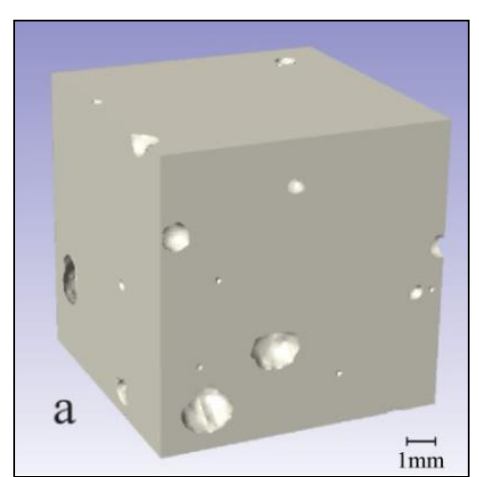

a) Control (A)

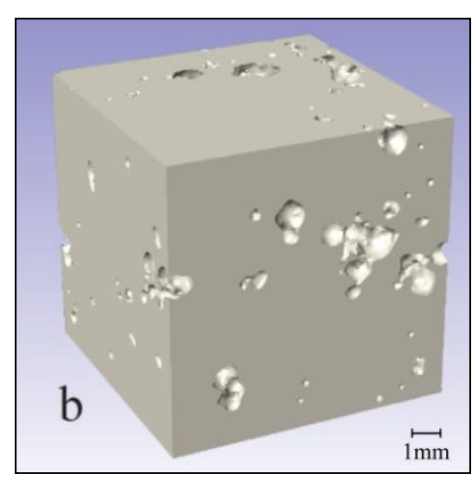

b) $0.1 \%(\mathrm{~A})$

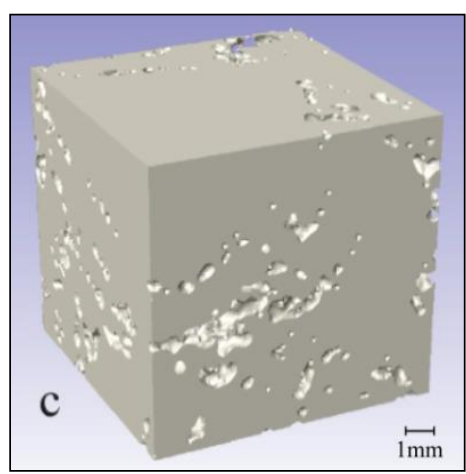

c) $0.2 \%(\mathrm{~A})$

Figure 8. Distribution of air voids

In Table 2 in Section 2.2, the listed slump results show that the admixtures stimulate the workability of concrete by reducing viscosity and preventing the formation of entrapped air voids, which are derived from settlement problems. By increasing the amount of admixture, entrained air voids are created instead of entrapped air voids; thus, the void ratio of specimens that are mixed with $0.1 \%$ of admixture are increased according to the control groups. By increasing the amount of admixture to $0.2 \%$, the void ratio of this group decreases to the void ratio of the control group. This differentiation is attributed to the varying qualifications of air void structures according to the mixed amount of admixtures.

\subsection{Dynamic Analysis}

The material properties of 3D modeled specimens are parametrized with the CDP model, which is based on the Abaqus library. Considering that the force is directly translated depending on the complex interactions between the rigid plates and the concrete's surfaces and the damage, large mesh 
deformations in the mesh structure are expected during the compressive test simulations. To properly characterize the mechanics of compressive test, the analysis is performed with an explicit solver, such as quasi-static simulation.

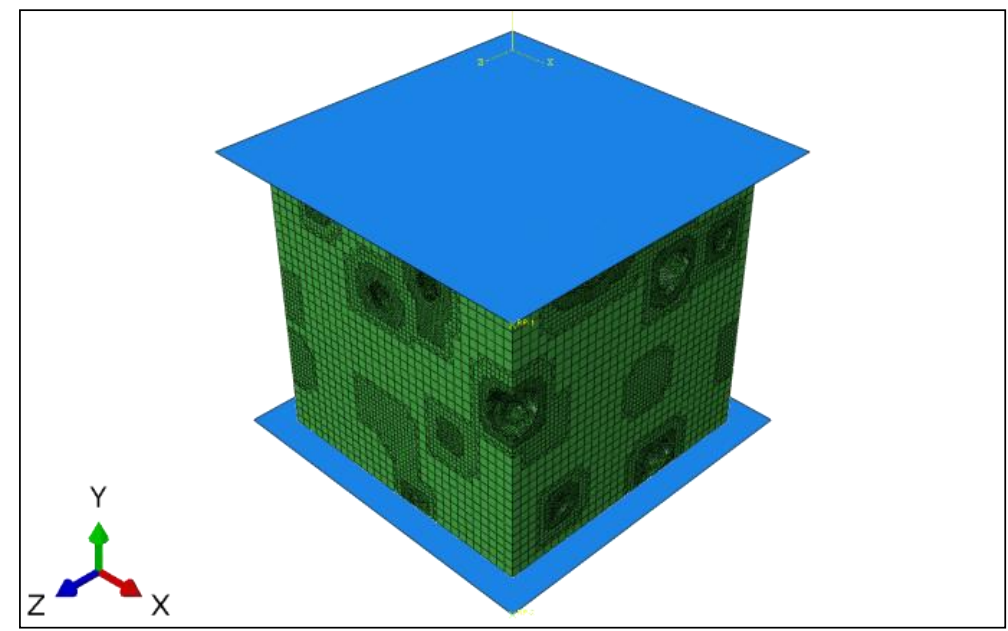

Figure 9. Compression test simulation

Bearing blocks are modeled as discrete rigid elements, whereas compressive tests are performed with steel bearing blocks. Due to the differences between the elasticity modulus and the Poisson ratio of the steel bearing blocks and the concrete, friction occurs between the steel platen's faces and the concrete's faces depending on varying magnitudes of deformations that develop in the vertical directions with the compression load. To realize the compression test conditions, the contact interactions between the rigid plates and the concrete models are frictional with a friction coefficient [14]; 0.57, finite sliding and surface-to-surface. The lower bearing block is supported as an encastre. The upper bearing block is free in the loading direction and is fixed in the remaining directions. During the analysis, the load was constantly applied as a periodic displacement.

The stress-strain curves, which are dependent on the displacement magnitude of $0.01 \mathrm{~mm} / \mathrm{s}$, are plotted in Figure 10, 11, 12, 13;

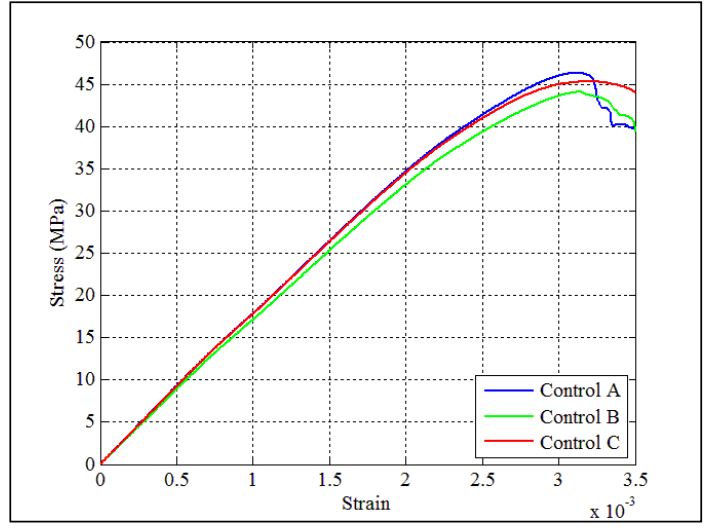

Figure 10. Control group

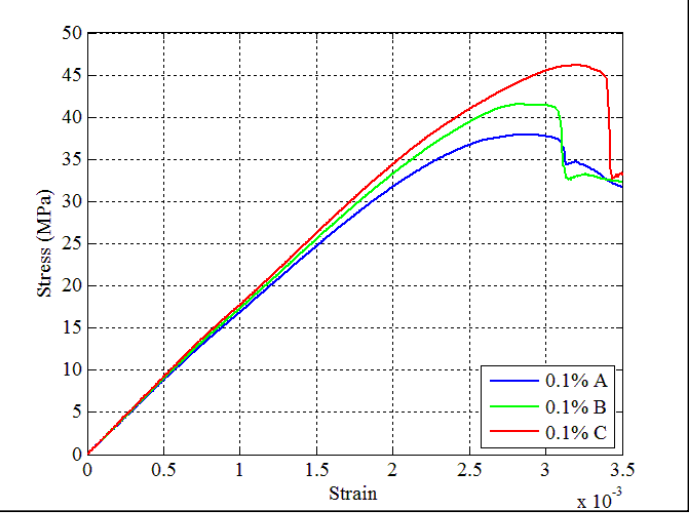

Figure 11. Group with $0.1 \%$ admixture 


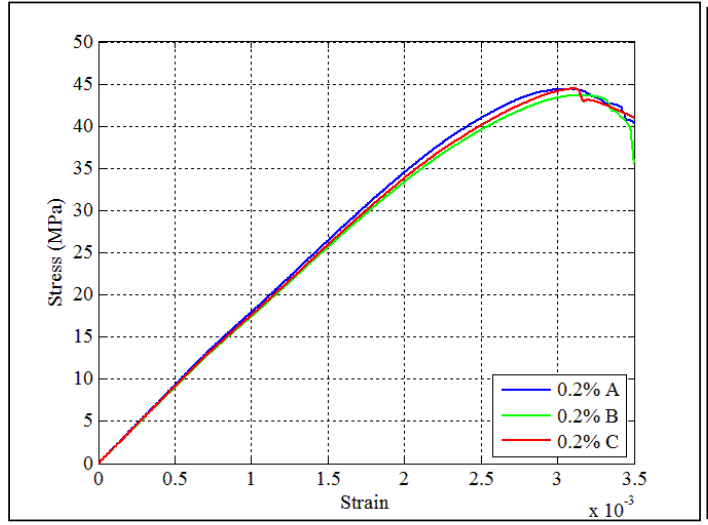

Figure 12. Group with $0.2 \%$ admixture

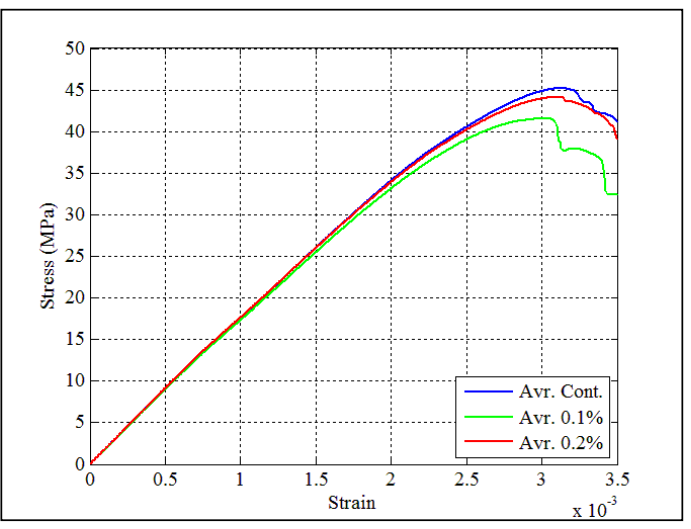

Figure 13. Average of groups

When we probe the ultimate compressive stress values, the U.S. values for the additive-free control group, as shown in Figure 10, and the U.S. values for the group with $0.2 \%$ of admixture, as shown in Figure 12, are approximately closer to each other depending on the similarity between their air void ratios. As shown in Figure 13, the average U.S. values for the control group, the group with $0.1 \%$ admixture and the group with $0.2 \%$ admixture are $45.21 \mathrm{MPa}, 41.55 \mathrm{MPa}$ and $44.15 \mathrm{MPa}$, respectively. According to the average U.S. value for the control group, the average U.S. value for the group with 0.1 decreased by $8.09 \%$ and the average U.S. value for the group with $0.2 \%$ negatively decreased by $2.33 \%$. The decrease can be attributed to the increase in air voids and the irregular micro architecture due to entrained and entrapped air voids. Beyond the ultimate stress peak point in the plastic region, the failure behavior for the group with $0.1 \%$, as shown in Figure 11, rapidly occurred compared with the control group, as shown in Figure 10, and the group with $0.2 \%$, as shown in Figure 12 , in which the failure behaviors consistently progressed.

The fracture patterns for the models that exceeded the ultimate compressive strength are shown in Figure 14.

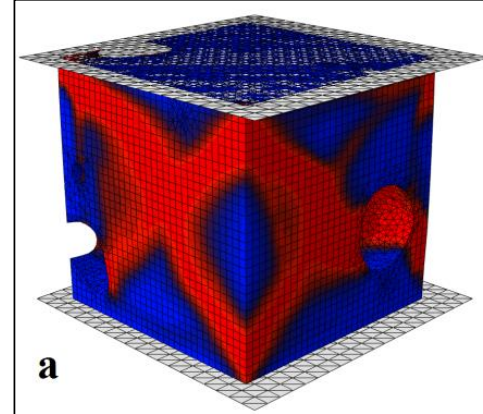

a) Control

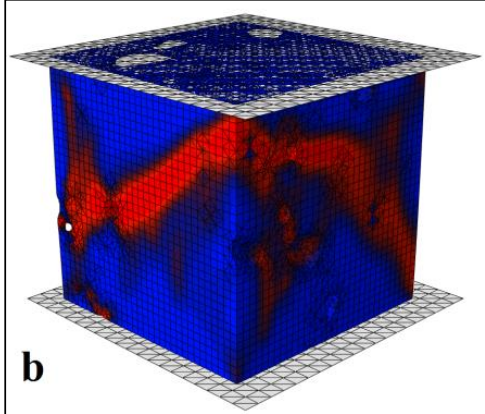

b) $0.1 \%$

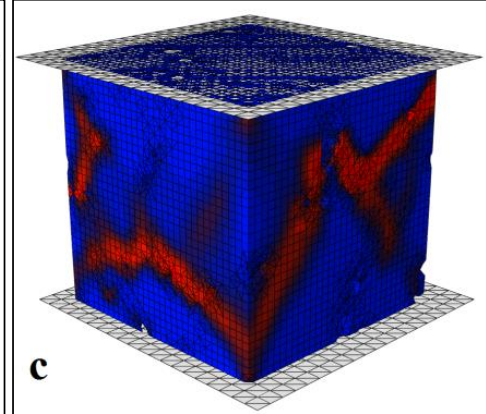

c) $0.2 \%$

Figure 14. Fracture patterns

As shown in Figure 14, the fracture patterns for the control groups, which have smaller ratios of micro air voids and are localized with major air voids, are formed across and between the corners due to the expected shear stresses. However, the patterns for the groups with admixtures are formed by passing over and between micro air voids and assumed irregular shapes due to the distribution of the micro air voids. This situation can be attributed to micro tensile cracks, which begin to form around micro air voids while concrete remains in the elastic region under uniaxial compressive stress. 
As shown in the cross-section of model A in Figures 15-16, which is located in the group with $0.1 \%$ admixture, the formation and propagation of tensile cracks, which is initially observed at the strain values of $\varepsilon=0.0003$, and increasing values of $\varepsilon=0.001$ and $\varepsilon=0.0015$.

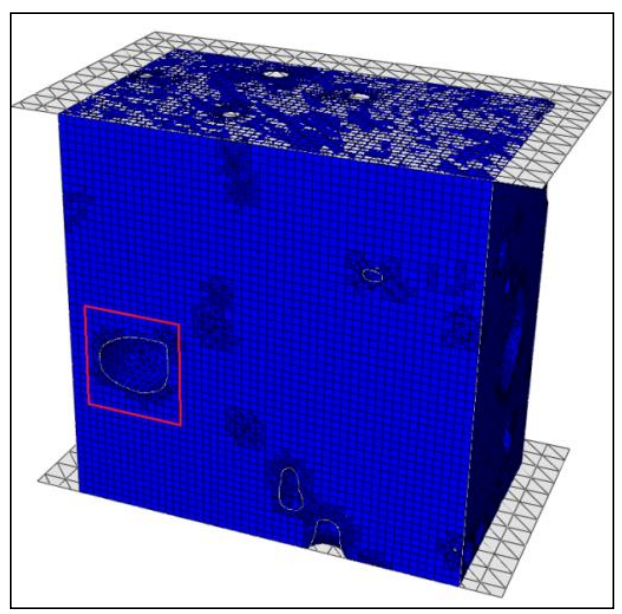

Figure 15. $0.1 \%$ cross-section of model A

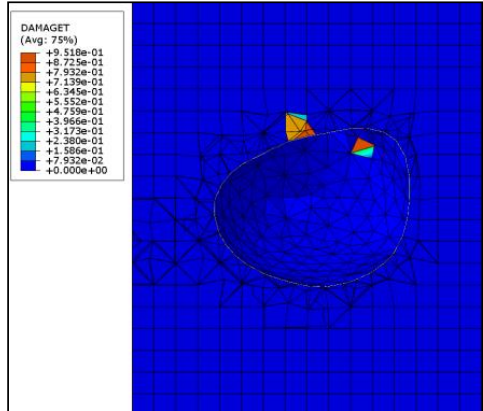

a) $\varepsilon=0.0003$

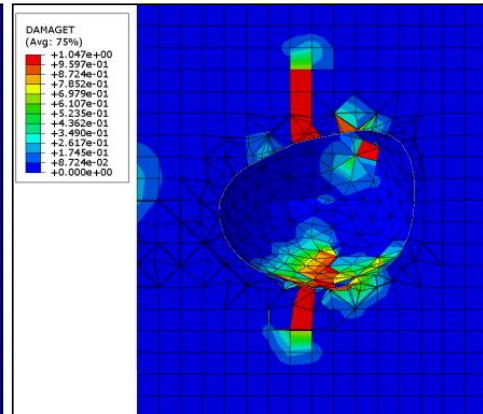

b) $\varepsilon=0.001$

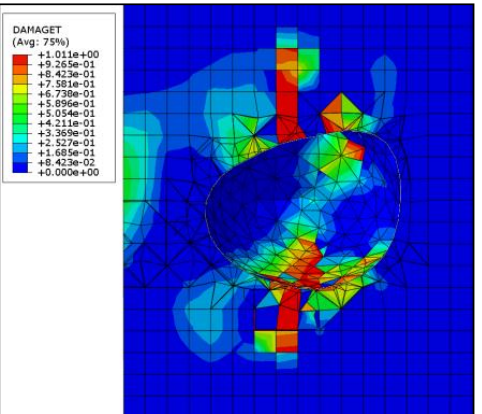

c) $\varepsilon=0.0015$

Figure 16. a, b, c. Developments and propagations of tensile cracks due to increasing strains

In Figure 17, the stress values that correspond to $\varepsilon=0.0003$, when the first tensile crack appeared, and $\varepsilon=0.001$ and $\varepsilon=0.0015$;

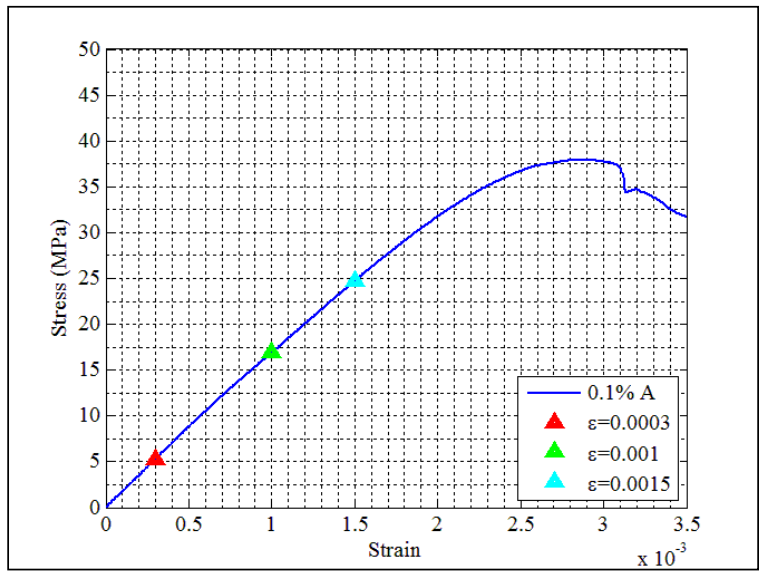

Figure 17. 0.1\% A model, in which the compressive stress values correspond to the crack propagations in Figure 16 
Due to the brittle structure of concrete under uniaxial compression, micro-tensile cracks, which form in the internal structure of concrete at lower values of compressive stress, substantially affect the ultimate compressive strength of concrete. When the first tensile crack appears at $\varepsilon=0.0003$, the compressive stress is approximately 5.30 MPa. Although the concrete remains in the elastic region, these micro cracks affect crack development and fracture patterns at the U.S. peak point. Therefore, the homogeneous distribution of the void structures that form in the internal structures of brittle materials, such as concrete, should be considered.

\section{CONCLUSION}

Air-entraining admixtures, which are mixed with concrete to improve its resistance to the effect of cyclic freeze-thaw, affect the plastic consistency and workability of concrete and substantially affect the qualifications and amounts of void structures. Therefore, the amount of admixtures is important.

The correlation of the air contents of hardened concrete with the methods for determining the air contents of fresh concrete were inadequate. The U.S. values for concrete are significantly impacted by the qualifications and distributions of void structures compared with the amount of void structures. Regarding the void structures of the groups, entrained air voids form when the amount of admixtures, entrapped air voids with diameters greater than $1 \mathrm{~mm}$, which are localized and derived from settlement problems, decrease. However, the group with $0.1 \%$ admixture have both entrapped air voids and entrained air voids; thus, the average U.S. value for the group with $0.1 \%$ admixture are negatively affected and decrease according to the U.S. values for the control group and the group with $0.2 \%$ admixture. Regarding the distributions of air voids, the group with $0.1 \%$ admixture is more cumulative than the group with $0.2 \%$ admixture. The group with $0.1 \%$ admixture is inadequate providing concrete's durability against the effect of cyclic expansion-shrinkage.

Ultimate fracture patterns are specified by the distribution of air voids, which is the main reason for the brittle structure of concrete. Micro-tensile crack propagations, which originate from inner tensile stresses, affect the U.S. values of concrete and fracture patterns. The analysis of porous, brittle materials with FEM indicates that the selection of a damage model, which considers the formation of tensile cracks and stiffness degradation, can be employed to obtain converging results. The concrete damage plasticity model, which considers these mechanical behaviors, provides an accurate analysis.

\section{ACKNOWLEDGEMENTS}

The authors gratefully acknowledge the ESOGU Scientific Research Fund (ESOGU-BAP grant number 201315023 ) for the financial support of this research.

\section{REFERENCES}

[1] Ozyildirim Ç. Location of air-entraining additives in concrete Durability. EKutuphane.imo.org.tr, 2007.

[2] ASTM. C457-Standard test method for microscopical determination of parameters of the air-void system in hardened concrete, 1998.

[3] Arslan B, Canbaz M, Sengel, HS. The Determination of the air entrained distribution in concrete using micro-ct and microscopic techniques experimental studies. In: Proceedings of the Fourtenth International Conference on Civil, Structural and Environmental Engineering Computing, Civil Comp. Press, 2013, Italy.

[4] 3D image processing software from Simpleware. http://www.simpleware.com/software/scanip/ 
Arslan et al. / Eskişehir Tech. Univ. J. of Sci. and Technology A-Appl. Sci. and Eng. 20 (3) - 2019

[5] Abaqus/CAE-Dassault Systèmes. http://www.3ds.com/productsservices/simulia/products/abaqus

[6] Abaqus 6.13 Analysis User's Guide. Volume III: Materials, Section 23.6.3. Inelastic Mechanical Properties, Concrete, "Concrete damaged plasticity"

[7] ASTM. C143-Standard test method for slump of hydraulic-cement concrete, 1998.

[8] Pramono E. Willam K. Implicit integration of composite yield surfaces with corners. Eng. Comput. 6, 1989; 186-197.

[9] Kachanov LM. Time of the rupture process under creep conditions, Izv Akad Nauk S S R Otd Tech Nauk. 8, 1958; 26-31.

[10] Chen, WF. Plasticity in reinforced concrete. Computer Methods Appl. Mech. Eng. 31, 1982.

[11] Kotsovos MDN. Behaviour of concrete under multiaxial stress, Int. J. Rock Mech. Min. Sci. Geomech. Abstr. 15, 1978.

[12] Petersson PE, Crack growth and development of fracture zones in plain concrete and similar materials, University of Lund, Lund, Sweden, 1981.

[13] Jankowiak T, Lodygowski T. Identification of parameters of concrete damage plasticity constitutive model, Found. Civ. Environ., 2005.

[14] Rabbat BG, Russell HG. Friction coefficient of steel on concrete or grout. J. Struct. Eng. 111, $1985 ; 505-515$. 